\title{
Peri-procedural Outcome of Small Vessel Coronary Stenting
}

\author{
Kazal Kanti Dan ${ }^{1}$, Mohammad Nazrul Islam² ${ }^{2}$ Md. Nur Hossain ${ }^{3}$, Mir Jamal Uddin ${ }^{4}$, AKM Monwarul Islam ${ }^{1}$
}

\begin{abstract}
:
Background: Among all percutaneous coronary interventions ( $\mathrm{PCls}), 30$ to $40 \%$ involve small coronary arteries. Small vessel PCI has historically been associated with poor outcome in terms of coronary artery dissection, acute vessel closure, myocardial infarction, emergent coronary bypass grafting, and restenosis, but the scenario has been changing in recent years. The outcome of small vessel coronary intervention in Bangladeshi population is largely unknown.
\end{abstract}

Objectives: The study was carried out to assess and compare the immediate outcome of $\mathrm{PCl}$ in small vessels with that in large vessels.

Methods: This prospective, comparative study involved 100 patients undergoing $\mathrm{PCl}$ with stent implantation; group I constituted $\mathbf{5 0}$ patients having target vessel diameter of $<3.0 \mathrm{~mm}$, whereas group II constituted 50 patients having target vessel diameter of $\geq 3.0 \mathrm{~mm}$. Immediate outcome of $\mathrm{PCl}$ was compared between the two groups. Angiographic, procedural and clinical successes were assessed. Acute complications e.g. major adverse cardiac events (MACE), arrhythmia, hemorrhage, pericardial tamponade, coronary dissection, no flow, vessel rupture and shock were observed.

Results: No statistically significant differences in baseline clinical characteristics existed between the two groups. Favourable outcomes were observed in both groups. Angiographic success was $100 \%$ in group I, as well as, in group II; procedural and clinical success was $94 \%$ vs. $98 \%$, and $90 \%$ vs. $94 \%$ in small and large vessel groups respectively ( $p>0.05$ ). Complications were infrequent in both groups. Also, no statistically significant difference was found in duration of hospital stay post-procedure between group I and group II.

Conclusion: Small vessel coronary stenting may be safe and effective. However, these findings require further study involving larger population and long term follow up.

Key words: Small vessel PCl, Coronary artery disease, Major adverse cardiac events.

(Bangladesh Heart Journal 2015; 30(1) : 22-26)

\section{Introduction:}

Percutaneous coronary intervention (PCI) is a commonly done procedure in the arena of interventional cardiology. This has revolutionized the management of coronary artery disease. However, the success of $\mathrm{PCl}$ is influenced by different factors including the vessel's size. Among all interventions, 30 to $40 \%$ involve small coronary arteries. ${ }^{1,2}$ Historically, small vessel intervention has been

1. Assistant Professor, Department of Cardiology, Jessore Medical College, Jessore. Email: kazal_dan@yahoo.com

2. Professor, Department of Cardiology, Bangabandhu Sheikh Mujib Medical University, Dhaka.

3. Professor,Department of Cardiology, Sir Salimullah Medical College \& Mitford Hospital, Dhaka.

4. Professor,Department of Cardiology, National Institute of Cardiovascular Diseases, Dhaka. associated with poor short term outcome in terms of significant vessel dissection, acute vessel closure, myocardial infarction and emergent coronary bypass grafting, and also worse long-term outcome in terms of restenosis. ${ }^{3-5}$ Furthermore, these lesions are frequently technically difficult in terms of device delivery and expansion because of non-compliance, calcification, tortuosity, and predominant distal location.

With further advancement in technology, hardwire and pharmacotherapy, the scenario began to change. In recent years, favourable angiographic and clinical outcomes have been reported by a number of researchers. ${ }^{6-11}$ In Bangladesh, increasing number of coronary interventions is being done, anda portion of all 
$\mathrm{PCls}$ presumably involves small vessels. However, data regarding the outcome of coronary intervention in small vessels are almost non-existing in Bangladesh. The present study was carried out to determine the safety and efficacy of stent implantation in small coronary arteries.

\section{Materials and Methods:}

This prospective, comparative study was conducted in the National Institute of Cardiovascular Diseases (NICVD), Dhaka, from July 2004 to June 2005. The general objective of the study was to assess and compare the immediate outcome of $\mathrm{PCl}$ in small vessels with that in large vessels. The specific objectives were to assess and compare the angiographic, procedural and clinical success of $\mathrm{PCl}$ in small vessels with those in large vessels, and to assess and compare the complications of $\mathrm{PCl}$ e.g. major adverse cardiac events (MACE), arrhythmia, haemorrhage, pericardial tamponade, dissection, no flow, vessel rupture, and shock in small vessel coronary stenting with those in large vessel stenting. Small vessel lesion was defined as the lesion where the target vessel diameter was $<3 \mathrm{~mm}$. A total of 100 patients were studied, among them 50 patients had target vessel diameter of $<3.0$ and were considered as group I, and rest 50 patients had target vessel diameter of e"3.0 mm and were considered as group II. The study protocol was approved by the Institutional Review Board and informed consent was obtained from each subject. Exclusion criteria were: ostial lesion, bifurcated lesion, left main stenosis, graft vessel stenosis, left ventricular ejection fraction (LVEF) $<30 \%, \mathrm{PCl}$ in both large and small vessel in the same patient, primary and rescue $\mathrm{PCl}$, thrombus in target vessel and chronic total occlusion (CTO). Patients with similar types of variables such as age, sex, risk factors for coronary artery disease and anatomical characteristics of lesions were matched as close as possible.

Coronary angiographic findings were recorded before balloon dilatation and after stenting.Stenting was done as an elective procedure through the right femoral arterial approach. Premedication was done with aspirin, clopidogrel and midazolam. After femoral arterial puncture, 10,000 units of heparin was given intravenously. All the cases were predilated with balloons and balloon expandable stents were deployed in all the cases. Femoral sheaths were removed within 4 to 6 hours post-procedure. During hospital stay all patients were given aspirin $75 \mathrm{mg}$ and clopidogrel $75 \mathrm{mg}$ daily along with other medications as necessary.Procedural complications e.g.MACE, arrhythmias, haemorrhage, no flow, dissection, pericardial tamponade, cardiogenic shock were recorded. Post-procedural follow-up began immediately after completion of the intervention itself, and was done hourly for the first 6 hours and then every morning and evening, or even more frequently if indicated. Subjective evidence of chest pain, breathlessness and pain in the limb through which vascular access was made were looked for. Pulse, blood pressure, chest, peripheral pulses and vascular access site were examined. Bedside monitor parameters were noted and available medical records were scrutinized. Twelve-lead ECGs were done immediately and 24 hours after the procedure, before discharge, and as necessary. CK-MB level in blood was measured six hours after the procedure and as necessary. Patients were followed up thoroughly during hospital stay upto a period of two weeks postprocedure.

All patients were followed- up throughout the period of index hospitalization, and upto 2 weeks post-procedure or death.

The collected data were expressed in frequency, percentage, mean \pm standard deviation as applicable. Comparison between groups were done by unpaired Student's t test, chi-square test and Fisher's exact test. All data were analyzed by using computer based SPSS (statistical programme for social science) progamme (version 11). P values of less then 0.05 was considered as significant.

\section{Results:}

The present study was a prospective comparative study to assess the periprocedural outcome of small and large vessel coronary stenting, and also to compare between the two groups. A total of 100 patients, equal in small and large vessel group, were studied. Number of small vessel lesions treated was 58, and that of large vessel lesions was 56 . There were no statistically significant differences in baseline clinical characteristics between the two groups. (Table I). Favorable results were observed in both groups. The outcome of the procedure was compared in terms of success, complications and hospital stay. (Table II to VII). 
Table-I

Distribution of patients by baseline clinical parameters $(N=100)$.

\begin{tabular}{|c|c|c|c|}
\hline Parameters & Group I $(n=50)$ & GroupII $(n=50)$ & pvalue \\
\hline \multirow{2}{*}{$\begin{array}{l}\text { Age in years } \\
\text { (MeanSD) }\end{array}$} & 51.49 .7 & 49.19 .8 & $0.245^{a}$ \\
\hline & No. (\%) & No. (\%) & \\
\hline \multicolumn{4}{|l|}{ Sex } \\
\hline Male & $39(78.0)$ & $44(88.0)$ & $0.183^{b}$ \\
\hline Female & $11(22.0)$ & $6(12.0)$ & \\
\hline \multicolumn{4}{|l|}{ Risk factors } \\
\hline Dyslipidaemia & $46(92.0)$ & $48(96.0)$ & $0.399^{b}$ \\
\hline Smoking & $31(62.0)$ & $36(72.0)$ & $0.287^{b}$ \\
\hline Hypertension & $18(36.0)$ & $13(26.0)$ & $0.279^{b}$ \\
\hline Family $\mathrm{H} / \mathrm{o} C A D$ & $12(24.0)$ & $7(14.0)$ & $0.202^{b}$ \\
\hline Diabetes mellitus & $9(18.0)$ & $6(12.0)$ & $0.401^{b}$ \\
\hline \multicolumn{4}{|l|}{ Clinical diagnosis } \\
\hline Post MI angina & $31(62.0)$ & $37(74.0)$ & \\
\hline Unstable angina & $10(20.0)$ & $7(14.0)$ & $0.436^{b}$ \\
\hline Chronic stable angina & a 9(18.0) & $6(12.0)$ & \\
\hline \multicolumn{2}{|l|}{ Group I: <3.0 mm } & Group & $0 \mathrm{mr}$ \\
\hline
\end{tabular}

There were no statistically significant differences in baseline clinical characteristics between the two groups.

Table-II

Distribution of patients by angiographic success $(N=114)$.

\begin{tabular}{lcc}
\hline Success & Group I (n=58) & Group II ( $n=56)$ \\
& No. (\%) & No. $(\%)$ \\
\hline Yes & $58(100.0)$ & $56(100.0)$ \\
No & $0(0.0)$ & $0(0.0)$ \\
\hline Group I: $<3.0 \mathrm{~mm}$ & & Group II: $>3.0 \mathrm{~mm}$
\end{tabular}

All patients of both groups achieved cent percent angiographic success.

Table-III

Distribution of patients by procedural success $(N=100)$

\begin{tabular}{lccc}
\hline Success & $\begin{array}{c}\text { Group I }(n=50) \\
\text { No. }(\%)\end{array}$ & $\begin{array}{c}\text { Group II }(n=50) \\
\text { No. }(\%)\end{array}$ & PValue \\
\hline Yes & $47(94.0)$ & $49(98.0)$ & 0.308 \\
No & $3(6.0)$ & $1(2.0)$ & \\
\hline
\end{tabular}

Group I: $<3.0 \mathrm{~mm}$ Group II: > $3.0 \mathrm{~mm}$

$P$ value was reached from Fisher's exact test.

Procedural success was a bit higher in large vessel stenting group (98\%) in comparison to small vessel stenting group (94\%). However, the differences were not statistically significant ( $p>0.05)$.
Table-IV

Distribution of patients by clinical success $(N=100)$

\begin{tabular}{|c|c|c|c|}
\hline Success & Group I $(n=50)$ & Group II $(n=50)$ & P Value \\
\hline & No. (\%) & No. (\%) & \\
\hline Yes & $45(90.0)$ & $47(94.0)$ & 0.357 \\
\hline No & $5(10.0)$ & $3(8.0)$ & \\
\hline \multicolumn{2}{|c|}{ Group I: $<3.0 \mathrm{~mm}$} & Group II: > $3.0 \mathrm{~mm}$ & \\
\hline \multicolumn{4}{|c|}{$P$ value was reached from Fisher's exact test. } \\
\hline
\end{tabular}

Table-V

Distribution of patients by TIMI flow before and after stenting $(N=114)$.

\begin{tabular}{lccc}
\hline TIMI flow & $\begin{array}{c}\text { Group I } \\
(\mathrm{n}=58) \\
\text { No. }(\%)\end{array}$ & $\begin{array}{c}\text { Group II } \\
(\mathrm{n}=56) \\
\text { No. }(\%)\end{array}$ & $\begin{array}{c}\mathrm{P} \\
\text { Value }\end{array}$ \\
\hline Before stentingTIMI 2 & $3(5.2)$ & $2(3.6)$ & 0.516 \\
TIMI3 & $55(94.8)$ & $54(96.4)$ & \\
After stenting & & & \\
TIMI2 & $0(0.0)$ & $0(0.0)$ & - \\
TIMI3 & $58(100.0)$ & $56(100.0)$ & \\
\hline
\end{tabular}

Group I: $<3.0 \mathrm{~mm} \quad$ Group II: $>3.0 \mathrm{~mm}$

$P$ value was reached from Fisher's exact test.

Between the groups, there were no statistically significant differences in baseline TIMI flow status. All patients in both group achieved TIMI 3 flow post procedure.

Table-VI

Distribution of patients by complications during the procedure $(N=100)$.

\begin{tabular}{lccc}
\hline Complications & $\begin{array}{c}\text { Group I } \\
(\mathrm{n}=50) \\
\text { No. }(\%)\end{array}$ & $\begin{array}{c}\text { Group II } \\
(\mathrm{n}=50)\end{array}$ & $\begin{array}{c}\mathrm{P} \\
\text { No. }(\%)\end{array}$ \\
\hline None & $47(94.0)$ & $48(96.0)$ & 0.684 \\
New Q wave MI & $3(6.0)$ & $1(2.0)$ & 0.309 \\
Cardiogcnic shock & $1(2.0)$ & $1(2.0)$ & 0.747 \\
Arrhythmia* & $0(0.0)$ & $1(2.0)$ & 0.505 \\
Hacmorrhage & $1(2.0)$ & $0(0.0)$ & 0.495 \\
Dissection & $1(2.0)$ & $0(0.0)$ & 0.495 \\
\hline
\end{tabular}

Ventricular tachycardia

Group I: $<3.0 \mathrm{~mm} \quad$ Group II: $>3.0 \mathrm{~mm}$

$p$ values were reached from Fisher's exact test.

Other than arrhythmia, complications during the procedure were more common in small vessel stenting group in comparison to large vessel stenting group, however, the differences were not statistically significant $(p>0.05)$. 
Table-VII

Distribution of patients by average hospital stay after stenting $(N=100)$.

\begin{tabular}{|c|c|c|c|}
\hline & 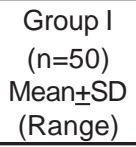 & $\begin{array}{l}\text { Group II } \\
(n=50) \\
\text { MeanSD } \\
\text { (Range) }\end{array}$ & $\begin{array}{c}\mathrm{P} \\
\text { Value }\end{array}$ \\
\hline $\begin{array}{l}\text { Average hospital stay after } \\
\text { Stenting (days) }\end{array}$ & $\begin{array}{l}6.02 .6 \\
(4-16) \\
\end{array}$ & $\begin{array}{l}5.61 .5 \\
(3-11) \\
\end{array}$ & 0.329 \\
\hline Group I: $<3.0 \mathrm{~mm}$ & Group & $\mathrm{mm}$ & \\
\hline
\end{tabular}

Average hospital stay post-procedure was a bit higher in small vessel stenting group in comparison to large vessel stenting group, however, the differences were not statistically significant $(p>0.05)$.

\section{Discussion:}

The present study was a prospective case-control study conducted in the NICVD, Dhaka. The aim of the study was to observe the success and complications of stenting in small coronary arteries. Overall,successful periprocedural outcome with insignificant complications were observed. The observational findings were consistent with those of many studies published in the reputed journals of home and abroad. ${ }^{12-4}$ To observe the periprocedural outcome, success was assessed in terms of angiographic, procedural and clinical success. Complications like MACE and minor complications were observed. In the present study patients underwent coronary stenting for post myocardial infarction angina (68\%), unstable angina (17\%) and chronic stable angina (15\%); there was no statistically significant difference in distribution between the groups. Stenting was done electively in all the cases in native coronary arteries. Symptomatic improvement was remarkable indicating clinical success. New Q waves appeared in $6 \%$ and $2 \%$ of cases in small and large vessel group respectively. There was no residual stenosis in any lesions of either group. Angiographic success was achieved in $100 \%$ of cases in each group. This correlates well with the study of Ali et al. ${ }^{15}$ Uddin et al. reported $96 \%$ angiographic success rate. ${ }^{12}$ In the current study both groups showed TIMI III flow in the distal vessels immediately after intervention. Anginal pain subsided in most of the cases in each group. After the intervention CCS class II and IV symptoms were observed in $10 \%$ and $6 \%$ cases in small and large vessel group respectively. The remaining were asymptomatic. Procedural success rate was $94 \%$ and $98 \%$ in small and large vessel group respectively.
So, clinical success was obviously high, $90 \%$ and $94 \%$ in small and large vessel group respectively. This correlates well with the study of Rahman et al. ${ }^{16}$ Acute lumen gain were $2.33+0.24 \mathrm{~mm}$ and $2.86+0.46$ $\mathrm{mm}$ in small and large vessel group respectively. Target vessel diameter, minimal lumen diameter (before and after stenting) and acute lumen gain are obviously low in patients with small vessels. But the difference of acute lumen gain by percentage between the groups was not statistically significant $(p>0.05)$. Residual stenosis was higher in the study of Koning et al. in comparison to the present study. ${ }^{13}$ The incidence of cardiogenic shock was equal (2\%) in both the groups. Only $1(2 \%)$ patient in large vessel group suffered from sustained ventricular tachycardia. Haemorrhage from vascular access site occurred in $2 \%$ in small vessel group with none in the large vessel group.

\section{Limitations of the Study:}

Despite exercise of caution, the study has got some limitations. The sample size was relatively small. Sampling method was consecutive, not random. Also, multivariate analysis was not done. There may be some role of confounding factors as well.

\section{Conclusion:}

In the present study, high angiographic, procedural and clinical success andlow complication rate was observed in small vessel coronary stenting, as well as, in large vessel stenting. So, small vessel coronary stenting may be safe and effective. These findings require further study involving larger population and long term follow up.

\section{Financial Disclosure: None.}

\section{References:}

1. Bourassa MG, Lespérance J, Eastwood C, et al. Clinical, physiologic, anatomic and procedural factors predictive of restenosis after percutaneous transluminal coronary angioplasty. J Am Coll Cardiol. 1991 Aug;18(2):368-76.

2. Foley DP, Melkert R, Serruys PW. Influence of coronary vessel size on renarrowing process and late angiographic outcome after successful balloon angioplasty. Circulation. 1994 Sep;90(3):1239-51.

3. Schunkert H, Harrell L, Palacios IF. Implications of small reference vessel diameter in patients undergoing percutaneous coronary revascularization. J Am Coll Cardiol. 1999 Jul;34(1):40-8.

4. Ellis SG, Vandormael MG, Cowley MJ, et al. Coronary morphologic and clinical determinants of procedural 
outcome with angioplasty for multivessel coronary disease. Implications for patient selection. Multivessel Angioplasty Prognosis Study Group. Circulation. 1990 Oct; 82(4):1193-202.

5. Hirshfeld JW Jr, Schwartz JS, Jugo R, et al. Restenosis after coronary angioplasty: a multivariate statistical model to relate lesion and procedure variables to restenosis. The M-HEART Investigators. J Am Coll Cardiol. 1991 Sep;18(3): 647-56..

6. Umeda $\mathrm{H}$, Iwase $\mathrm{M}$, Kanda $\mathrm{H}$, et al. Promising efficacy of primary gradual and prolonged balloon angioplasty in small coronary arteries: a randomized comparison with cutting balloon angioplasty and conventional balloon angioplasty. Am Heart J. 2004 Jan;147(1):E4.

7. Casella G, Prati F; Multi-Link PIXEL Multicenter Italian Registry. Stenting small coronary arteries: The Multi-Link PIXEL Multicenter Italian Registry. J Invasive Cardiol. 2003 Jul;15(7):371-6.

8. Airoldi F, Di Mario C, Presbitero P, et al. Elective stenting in small coronary arteries: results of the Italian prospective multicenter registry MICROSCOPE. Ital Heart J. 2002 Jul;3(7):406-11..

9. Seabra-Gomes R, Almeida M, Cavaco D, et al. Results of the quantitative coronary angiographic analysis in the angiographic subgroup of the MultiLink 2.5 Portuguese Registry. Rev Port Cardiol. 2001 Sep;20(9):841-55.

10. Moer R, Myreng Y, Mølstad P, et al. Stenting in small coronary arteries (SISCA) trial. A randomized comparison between balloon angioplasty and the heparin-coated beStent. J Am Coll Cardiol. 2001 Nov 15;38(6):1598-603..

11. Park SW, Lee CW, Hong MK, et al. Randomized comparison of coronary stenting with optimal balloon angioplasty for treatment of lesions in small coronary arteries. Eur Heart J. 2000 Nov;21(21):1785-9.

12. Uddin MJ, Chowdhury AHK, ALi M, et al. Percutaneous coronary intervention $(\mathrm{PCl})$ result of 100 cases. Bangladesh Heart Journal 2003; 18: 109-15.

13. Koning R, Eltchaninoff $\mathrm{H}$, Commeau $\mathrm{P}$, et al.; BESMART (BeStent in Small Arteries) Trial Investigators. Stent placement compared with balloon angioplasty for small coronary arteries: inhospital and 6-month clinical and angiographic results. Circulation. 2001 Oct 2;104(14):1604-8.

14. Savage MP, Fischman DL, Rake R, et al. Efficacy of coronary stenting versus balloon angioplasty in small coronary arteries. Stent Restenosis Study (STRESS) Investigators. J Am Coll Cardiol. 1998 Feb;31(2):307-11.

15. Ali MR, Haque KMHSS, Ahmed QS, Rahman M, Haque SA. Short term outcome of percutaneous transluminal angioplasty with and without stent in the treatment of coronary artery disease. Chest \& Heart Journal 2002; 26: 14-20.

1. Rahman S, Masky A, Akanda AK, Malik F, Ahmed N. Prediction of immediate outcome of intracoronary stent implantation by lesion morphology. Bangladesh Heart Journal 2001; 16: 1-8. 